\title{
Young Athletes' Perceptions of Coach-Athlete Sexual Relationships: Engaging With Competing Ethics
}

\author{
Kari Stefansen \\ Oslo Metropolitan University \\ Gerd Marie Solstad and Åse Strandbu \\ Norwegian School of Sport Sciences \\ Maria Hansen \\ Oslo Metropolitan University
}

\begin{abstract}
In this paper, we use data from focus group interviews with young athletes to explore their thinking about coach-athlete sexual relationships (CASRs). Our aim is to further the understanding of the ambivalence surrounding CASRs in the sports field, which are simultaneously viewed as ethically problematic and acceptable - at least when they involve high-profile adult athletes. Inspired by Swidler's toolkit approach to culture, we analyze how athletes understand and justify CASRs. We found that three different ethics were activated in the interviews: the safeguarding, love, and athletic-performance ethics. We discuss how these ethics are linked to different underlying "imaginaries," or cultural frames, about the meaning of sport in society and offer thoughts on how the results can inform sporting organizations' future prevention efforts.
\end{abstract}

In this paper, we explore coach-athlete sexual relationships (CASRs) from the perspective of young athletes, with the aim of adding to the evolving research on CASRs as a contested social phenomenon. Our starting point is what we see as two conflicting images of such relationships in contemporary sport culture. The first is a positive image in which a highly successful female elite athlete is in a relationship with a professional, well-regarded husband coach. This "dream team" image suggests that CASRs are a natural part of sports and are often beneficial for individual athletes. In Norway (our context of study), some of the most successful female athletes of all time have indeed had husband coaches. One well-known example is the long-distance runner Grete Waitz (see Tjelta, Tønnessen, \& Enoksen, 2014), active in the 1970s and '80s, who won nine New York Marathons and took medals in several global championships. A more recent example is the mountain biker Gunn-Rita Dahle Flesjå, Olympic champion and repeat gold medalist in world and European championships, whose career began in the 1990s and continues today. Other high-profile cases may be found in popular team sports such

\footnotetext{
(C) 2019 The Authors. Published by Human Kinetics, Inc. This is an Open Access article distributed under the terms of the Creative Commons Attribution License CC $\mathrm{BY} \mathrm{NC}$ 4.0, which permits unrestricted noncommercial use, distribution, and reproduction in any medium, provided the original work is properly cited, the new use includes a link to the license, and any changes are indicated. See http:// creativecommons.org/licenses/by-nc/4.0. This license does not cover any third-party material which may appear with permission in the article. For commercial use, permission should be requested from Human Kinetics, Inc., through the Copyright Clearance Center (http://www.copyright.com).
}

Stefansen and Hansen are with Oslo Metropolitan University, Oslo, Norway. Solstad and Strandbu are with Norwegian School of Sport Sciences, Oslo, Norway. Address author correspondence to Kari Stefansen at karis@oslomet.no. as handball, including Heidi Løke, who has played on the very successful Norwegian national team for over a decade.

The second is a negative image in which such relationships are viewed as possibly exploitative and in conflict with new ideals in sport coaching based on the clear separation of the private from the professional. In this image, CASRs are often portrayed as being at odds with a healthy and modern sport culture. This second image is found in the current codes of conduct and ethical guidelines for coaches issued by an increasing number of sport organizations.

While sport organizations have shown a marked increase in the attention they pay to CASRs, the topic remains under-researched in sport sociology (Fasting, Sand, \& Sisjord, 2018; Johansson \& Larsson, 2017), at least from perspectives other than the sexualabuse framing (Johansson, 2013). Existing CASR research has also focused primarily on the elite level. Studies have been conducted both on coaches' opinions on the subject (Fasting et al., 2018) and on athletes' experiences with such relationships (Johansson, 2018; Johansson \& Larsson, 2017). Less is known about athletes' viewpoints on CASRs. As athletes are both recipients and active interpreters and co-creators of sport culture (cf. Coakley \& Pike, 2009), an analysis of why CASRs occupy such an ambivalent position in the sports field must include their perspectives and modes of reasoning.

In this paper, we analyze data from focus group interviews with bachelor-level sports students who were active in organized sports while growing up: most in recreational sports, and some at the elite level. A few were still active, and half had coaching experience. We refer to them as "athletes" because the interviews focused on their viewpoints as insiders in the sports community. Our focus in this paper is CASRs as related to couple relationships between athletes and their coaches; other definitions may also include casual sexual relationships (Johansson, 2018; Johansson \& Larsson, 2017). 


\section{Background: Safeguarding in Sport}

An increasing number of sport-governing organizations have developed ethical guidelines and codes of conduct for coaches (Fasting et al., 2018; Johansson, 2013; Lang, Mergaert, Arnaut, \& Vertommen, 2018). In Norway, guidelines on sexual harassment and abuse have been in place at the national level since the early 2000s, with the latest version issued in 2010 by the Norwegian Olympic and Paralympic Committee and Confederation of Sports (NIF, from "Norges idrettsforbund"). On the surface, these guidelines communicate the simple message that CASRs are unwanted. The guidelines state that "dual relationships" should be avoided; they further add that if reciprocal relationships are established, then the other participants in the sporting milieu should be informed of the relationship. ${ }^{1}$ The add-on about reciprocal relationships-and the idea that openness will reduce some of the dilemmas that arise from them-means that the guidelines communicate a somewhat conflicting image of CASRs. CASRs are addressed within guidelines on sexual harassment and abuse, which clearly signals that such relationships hold no place in sports. Still, such relationships - if reciprocal — can be tolerated if handled professionally, hence offering the possibility of a form of conditional acceptance. While the topic is not specified in the guidelines, it seems reasonable to view the Norwegian guidelines as addressing two forms of CASR: legal CASR (involving consenting adults) and illegal CASR (involving a minor below the age of consent). In Norway, the former would mean relationships where both parties are 16 years or older. The organization communicates a stricter policy on its website, however, using a commanding tone towards coaches: "Do not abuse your power and authority. There is zero tolerance for sexual advances and intimate contact with athletes.",2

The International Council of Coaching Excellence (ICCE) and the US Olympic Committee (USOC) have developed similarly strict rules, emphasizing coaches' duty not to engage in sexual relationships with their athletes and to discourage any attempts by athletes to initiate relationships with them. These stricter guidelines make no exceptions for legal CASRs. Interestingly, the guidelines offer two very different rationales for this position: one based on individual rights for protection from exploitation and one based on the risk that CASRs may hamper the possibility of athletic success. Some guidelines may also emphasize the reputation of sports as a safe space for children and young people, which is an idea related to the first rationale (Johansson, Kenttä, \& Andersen, 2016).

\section{Research on CASRs}

Of the few empirical studies that have been conducted on CASRs, most have been small-scale and explorative in nature (Johansson, 2018; Johansson \& Larsson, 2017; Jowett \& Meek, 2000). A key theme in these studies is how coaches make sense of the CASR phenomenon and its place in sports (Bringer, Brackenridge, \& Johnston, 2002; Johansson et al., 2016). One recent example is Fasting et al.'s (2018) interview study among 36 elite-level coaches in Norway, including some who were (or had been) in a relationship with an athlete on their team. The coaches generally disapproved of CASRs, based on concerns that they could compromise the integrity of the coach and have a negative impact on the athletes and team dynamics. They further felt that if such relationships are to be established, then they should be discussed openly, and that one of the two parties should ideally leave the team or practice group. The coaches' opinions clearly mirrored the official guidelines issued by NIF-and the idea of conditional acceptance. Fasting et al. (2018) interpret the coaches' strictness as a display of political correctness and the ongoing professionalization of the coaching role.

These findings differ strikingly from a survey study conducted in Denmark and published 17 years earlier (Nielsen, 2001), i.e. around the time when ethical guidelines for coaches were beginning to appear. In that study, two-thirds of the participating coaches from four different sports answered that it was acceptable for a coach to have an intimate relationship with an athlete over the age of 18-i.e. relationships that would constitute legal CASRs. Mindful of the differences in context and methodology between these two studies, we may hypothesize that coaches' ethical standards have changed during the last two decades, especially in elite or professional sports.

Only a few studies on athletes' perspectives on CASRs have been conducted to date. Johansson and Larsson (2017) interviewed four female elite athletes about their own experiences with CASRs, while Johansson (2018) analysed a single case of a CASR involving a same-sex couple (a young elite athlete and a considerably older coach). These studies illustrate some of the problems of defining CASRs as sexual abuse or deviant practices and applying regulations based on a zero-tolerance perspective. For example, banning CASRs might potentially foster practices of secrecy that could render the athlete more vulnerable.

The studies referenced above also illustrate how the meaning of a particular relationship depends on context and that drawing sharp boundaries between healthy and unhealthy relationships could be difficult. While relationships between coaches and athletes may be based on mutual love and desire (Johansson et al., 2016), they may also be the result of intentional grooming, i.e. the practice of building trust and breaking down interpersonal barriers as a precursor to abuse (Brackenridge \& Fasting, 2005; Fasting \& Brackenridge, 2005; Owton \& Sparkes, 2017). Still, we agree with Johansson et al. (2016) that there is a need for studying CASRs within broader contexts of meaning than sexual abuse. Doing so would mean moving beyond the "deterministic perspective" of CASR in which the inevitable negative consequences are placed in the foreground and instead using a "dualistic perspective" that separates legal and consensual CASRs from child sexual abuse (Johansson, 2013). As Johansson (2013) has commented, such an analysis would still need to take into account the fact that the meaning of consent in authority-subordinate relationships is difficult to assess. For instance, the athlete may re-evaluate what he or she wanted at the time as being non-consensual once the relationship has ended (e.g., Johansson, 2018). In this paper, we will follow Johansson and Larsson's lead (2017) by approaching CASR as a complex social phenomenon that results in several ethical dilemmas.

\section{Theoretical Framework}

Our study is situated within the field of cultural sociology, and we draw specifically on Swidler's (1986) idea of culture as a toolkit or repertoire "from which actors select differing pieces for constructing lines of action" (p. 277). In this theory, cultures are not understood as coherent systems but rather as containing diverse and often conflicting symbolic representations and guides to action and evaluation. Swidler's (2013) analysis of meaning-making around love relationships illustrates how the theory can be deployed in empirical analyses. In that study, she analysed not only "what [her] interviewees thought about love, but how they thought" (p. 4; emphasis in original). This means that the analysis 
encompassed both the differing views held by the same people and how lines of thinking and reasoning made sense within particular frames (Swidler, 2013). Swidler understands "frames" as being akin to Goffman's idea of "cultural frames," i.e. as situations that structure what is possible to mean and articulate about a particular issue.

What we take from this notion is that an analysis of athletes' reasoning about CASRs must identify and theorize cultural frames in addition to any concrete positions the athletes take on the legitimacy of CASRs. This reasoning accords with Swidler's (2013) argument that within the culture-as-toolkit approach, the analysis shifts from simply being about the views of particular people on a specific issue to focussing instead on the cultural resources themselves that people pick up and put aside in order to make sense of a given phenomenon.

Based on this background, the aim of our analysis is both to identify any lines of thought that are activated in discussions about CASRs as a moral issue and the broader cultural frames that different lines of thought make sense within. For the latter purpose, we also draw inspiration from a theoretical strand within cultural sociology associated with the work of Boltanski and Thévenot (2000, 2006), which explores how judgement is situated in particular "regimes of justification." Such regimes refer to "principles of evaluation which individuals deploy in the process of trying to define what may be the most proper or legitimate action or standard of action and whereby they grope for or re-establish social agreement" (Silber, 2003, p. 429). A key point on this subject is that people navigate between different regimes of justification that transcend the particular situational context of their problems. The concept of "legitimate orders of worth" is central to Boltanski and Thévenot's $(2000,2006)$ framework and refers to different rationalities that are called upon to justify a moral stance: for instance the market order and the civil order. While we have thought along these lines in our analysis, we have concentrated on orders of worth in a more restricted sense by attempting to grasp how athletes' reasoning about CASRs relates to understandings of the relationship between sport and society at large.

Based on this analysis, we argue that some of the confusion surrounding CASRs in the sport field stems from a more general ambivalence about the role of sport in society, and specifically on whether or not sport occupies a special position above or beyond society at large that has its own logic and morality.

\section{Methodology}

To illuminate athletes' understandings of CASR, we have analyzed data from a focus group interview study with sport students $(n=$ 106; age span 19-26). A team of researchers and $\mathrm{PhD}$ students (ten women, five men) conducted 20 gender-mixed focus group interviews. The interviewers obtained informed consent prior to the interviews and provided the project leader's (the third author's) contact information in case the participants wanted to talk to someone about sexual harassment or abuse. A one-page questionnaire distributed at the end of the interview was used to collect background information on the participants, including their sport and coaching experiences. ${ }^{3}$ We consulted the Norwegian Centre for Research Data on the ethical aspects of the project; the centre concluded that the project did not need to be submitted for further ethical evaluation.

The focus group methodology was chosen because it provides important information about participants' everyday language, including slang and jokes. It also allows for observation of the processes through which meaning is constructed, confronted, and debated among participants. Hence, the methodology is sensitive to cultural and sub-cultural values and underlying cultural dilemmas, the latter being what this study explores related to CASRs.

We used four short films involving a coach and an athlete in different situations that could be interpreted as having a sexual or intimate dimension to launch discussions. This methodological approach is often referred to as the "video elicitation interview" approach (e.g., Henry \& Fetters, 2012). The films were low-cost productions featuring sport students as actors and produced by NIF as part of an effort to raise awareness of sexual harassment in sport. ${ }^{4}$ The films worked as a common starting point across the interviews and as a resource for the moderators to engage the participants in further deliberations. Being quite amateurish, the films also may have helped to loosen up the situation by allowing for less serious, "back-stage" comments.

In each film, the coach and athlete appear to be quite close in age; both are in their early 20s. The series of films is entitled The Coach's Responsibility, and they end with the film's topic appearing on the screen, followed by the question "What is OK?" In the following, we analyze discussions related to the film Being Romantically Involved with One of the Athletes, which starts with a female swimmer finishing a lap and getting out of the pool. The coach praises her on her effort and places his arm around her waist. He then addresses four other swimmers sitting by the pool and rounds off the training session. While still in front of the group, he invites the swimmer he had praised over to his house for dinner. She smiles and accepts, before they walk off together. The film ends with one of the other swimmers asking the group, "Am I the only one who thinks this is strange?"

After the film, the participants were invited to evaluate the situation. Variations of the following questions were posed: What is going on in this situation? Is the coach's behavior appropriate? Are the intentions of the coach important? How do you interpret the athlete's reaction? Could/should the coach have done something differently? What about the athlete? We also explored how the students' perceptions of the situation changed as we modified the athlete's age, the age difference between the coach and the athlete, and the gender constellation of the couple.

The interviews lasted 50-60 minutes on average. They were audio-taped, transcribed verbatim, and anonymized. The quotes in this paper have been edited very lightly for clarity in English. The interviews were analyzed thematically (Braun \& Clarke, 2006) in a two-step procedure. First, we identified all passages that involved discussion about CASRs; then we searched these parts for recurring themes. Following Grover and Nangle (2003), a theme in this case refers to issues that were discussed in depth in the majority of interviews. We identified three main themes related to CASRs that we understand as representing different moral codes, or "ethics," that could be activated in the interview setting for the purpose of making sense of CASRs.

\section{Analysis}

We have labeled the moral codes for evaluating CASRs that emerged from the interviews as (1) the safeguarding ethic, (2) the love ethic, and (3) the athletic-performance ethic. Below we describe the core rationale of each and show how they informed the athletes' evaluations of CASRs. Following this descriptive analysis, we discuss how the three ethics relate to wider "orders of worth" linked to the role of sport in society. The analysis centers on 
CASRs involving a male coach and a female athlete, as this pairing was what CASR represented for the athletes in our study.

\section{(1) The Safeguarding Ethic: An Athlete's Need for Protection}

The safeguarding ethic emphasizes the need to protect athletes, who are considered vulnerable vis-à-vis their coaches. A recurring theme in the interviews was the need to protect minors from being exploited. One athlete - probably referring to the legal age of sexual consent in Norway-commented that at 16, a person transfers "from being a child to becoming an adult." The athletes did not spend much time discussing "illegal CASR," i.e. relationships involving a minor. They perceived illegal CASR as morally wrong - in all cases. In this sense, the athletes' discussions mirrored the idea in various ethical guidelines that a line can be drawn by applying external criteria (e.g., the legal age of consent). Their deliberations instead differentiated between legitimate and illegitimate CASR involving athletes above the legal age of sexual consent (i.e., within the realm of "legal CASR"). While the statements in each interview indicated a sharp line between the legitimate and the illegitimate, the athletes did not draw the line at the same age across the interviews, which suggests that the topic was malleable and open for interpretation. Some groups drew the line at 18 or higher and thus also included junior teams as sites where CASRs were problematic, as the following quotes attest.

[At 18], you're responsible for your own life. (Girl 2, int. 7)

I don't think, in child and youth sports ... it's not okay to be in a relationship with an athlete. But if you do professional sports, and you're a real adult [around 20], then it should be okay, really. (Boy 3 , int. 2)

The age of the athlete was also important to the interviewees in relation to the age of the coach. They saw differences in age as being particularly problematic or indicative of the relationship being in a "grey area" when they considered the athlete to be young.

It's important to think about age [in relation to CASRs].... It can be okay if the athlete is 18 or 19, but not if you're 15 or 16; that's not okay.... That's too much of a difference.... It's a different power balance in the relationship. (Boy 3, int. 5)

I think it's strange with an 18-year-old and a 40-year-old, but it's okay, really. You can't say anything against [that kind of relationship]. (Boy 1, int. 7)

I think that when you start approaching your mid-20s, then the athlete knows-when the coach is older-what she wants and what's okay and not okay. But when you're 16 and an athlete and the coach [approaches you] then you're naive and don't really know what to do. Then it's much easier for mistakes to happen. I think so. Yes. (Boy, int. 12)

These quotes highlight the ambiguities surrounding legal CASRs that are thought to contain a power imbalance due to the athlete's young age or the age difference in the relationship. The second quote also communicates the fact that athletes can have difficulty defining or speaking up about problematic CASRs that fall within legal parameters. The use of words such as "strange" or "odd" signals a certain unease related to relationships that in principle are considered legitimate. In some interviews, the evaluation was more explicitly connected to the power difference between the coach and the athlete, as in the following quote related to a coach-athlete relationship with a ten-year age difference.

Well, then I think that [such a relationship has] a strange power relation. Especially if the relationship started after that power relation was established. Because between a coach who's 27 and an athlete who's 17 , there's a pretty big difference in terms of power. And I think that the athlete who's 17 very much looks up to that coach who's 27 , so that's-for me, that would be very strange. And not recommended. (Boy 1, int. 16)

We should also mention that in some of the interviews, the athletes concluded that legal CASRs were simply wrong because of the inherent risk that coaches would take advantage of their positional power vis-à-vis the athletes.

For a coach to do that [develop a relationship with an athlete] ... you've broken all trust ... for your own gain. You've taken advantage of the situation to do something else. You've gained information on that athlete that puts you in a position to ... trigger someone, or to ... be attentive to aspects of that person that make it possible to ... develop a relationship like that, instead of what athlete-coach relations are supposed to be like. (Boy 3, int. 20)

... even if [the relationship] is mutual and consensual ... even then it's ... wrong. (Boy 4, int. 20)

Although the athletes quoted above did not explicitly discuss the issue of gender, they did refer to relationships that in most cases involved a younger female athlete and an older male coach. Hence, the positional power and vulnerability they attributed to the coach and athlete (respectively) can be connected to both age and gender.

We saw across the interviews that the positioning of legal CASR as legitimate or not was fundamentally related to the construction of the athlete. When the athlete was understood to be an adult-someone mature who could take responsibility for herself-then the CASR became tolerable. In contrast, when the athlete was understood as being vulnerable due to age-related naivety or her inferior position, then the CASR became more problematic. Some of the interviewees questioned the very idea of legitimate CASR, thus mirroring the strict versions of codes of conduct and ethical guidelines and the perspective of the professional coaches interviewed by Fasting et al. (2018). In our material, this positon was less common than the more lenient position.

\section{(2) The Love Ethic: Feelings Cannot be Regulated}

The second ethic voiced in the interviews pivoted around love relationships as naturally occurring in sport. We coined this the "love ethic." In the athletes' view, valid relationships were based on love. From the love-ethic perspective, sport authorities do not have legitimate grounds for inhibiting legal romantic relationships between coaches and athletes. Love-based CASRs could still be problematic, however, depending on how the couple handled the situation, and particularly the degree of professionalism they displayed within the sport setting.

The athletes talked about love as something akin to destiny: a force that people cannot control, and hence is located outside the realm of what can be regulated.

You can't ... how can I put it, control who you develop feelings for. (Girl 2, int. 4) 
If it's true love, to put it like that, what can you do, really? (Boy 2 , int. 12)

... sport has its rules, but then ... love has its rules, or ... no rules, so then you can't [have rules against love]. It's a cliché, but there are more important things than sports, really. (Boy 2, int. 13)

These quotes mirror the findings from other studies. In Johansson and Larsson's (2017) study, for example, athletes who had been in couple relationships with their coaches spoke about love as an irrational and uncontrollable force that was impossible to resist. And in Fasting et al.'s (2018) study on professional coaches' perspectives, the female coaches expressed similar ideas and referred to love as something that "has no boundaries" and is "not something you can regulate" (p. 467).

The students in our study also drew on a "sport is life" discourse when talking about CASRs. In their view, love was likely to occur in the context of sport because of the amount of time athletes spend engaged in sport as well as the closeness and bonding that typically characterize sport milieus.

You spend a lot of time with a person and get to know that person well, and then it often happens that people will develop feelings for each other. So it's very natural that things can happen between a coach and an athlete who get to know each other that well. (Boy 3, int. 4)

When [the sporting milieu] is the place where you [spend] 24 hours of the week, then you'll find your partner there. Because that's the life you have, and there's not that much outside that milieu. (Girl 2, int. 15)

The second quote sums up a typical athlete's thinking: sport is where life happens, and love is a natural part of life, and hence love (between consenting adults) must be allowed in sports. This idea makes for an interesting contrast to the ideas expressed within the safeguarding framework discussed above, where some interviewees talked about how the trusting and close relationships that develop in sport may put athletes at risk of exploitation.

For the athletes to draw upon the love ethic, however, the manner in which the CASR was established was often a relevant factor. An already-established CASR represented a different situation from one in which the coach had become attracted to one of the athletes in the group. The participants viewed the latter type of CASR with more suspicion, perhaps due to the coach-athlete relationship becoming more visible in such a scenario:

If it's the coach who's arranged for [the relationship to begin], or started to flirt a little or something, then it might be that you're afraid that [the relationship] will affect your playing time if you're a footballer or, if you reject the coach, that it will affect you negatively.... As you say, there's an imbalance in power from the start ... if [the relationship] occurs when they're already in that type of relationship. (Girl 2, int. 16)

This quote alludes to the basis of a coach's power over athletes, where the coach can decide on the athletes' sport participation. The quote also indicates that the athletes viewed love-based relationships as being characterized by equality and reciprocity. As we will discuss in the next sections, the athletes were also concerned about how couples, once established as valid relationships, would manage the situation.
I think it's absolutely acceptable, but I think [such relationships] should be professional, that when you're at practice-if someone from the outside arrives - then that person shouldn't be able to see if [the coach and athlete are] in a relationship or not. (Girl 3, int. 6)

Especially if ... you're responsible for more athletes in a group. If you're coaching an individual athlete-it's a bit different. But the way [the film depicts the situation] ... it's obvious that one person gets more attention, and then you're very unprofessional. He doesn't keep his private life and the coaching role separate. And that's obviously a problem. (Boy 3, int. 4).

As these quotes indicate, displaying professionalism was important to the athletes. The issue of legitimacy and appropriateness hence moved from the relationship per se to the degree of professionalism the couple displayed. The athletes favoured a clear separation of the private and the professional: that the couple should "be open and honest about" their relationship (boy 2, interview 13) but still refrain from acting like a couple in front of the team. In this way, they could reach a workable compromise that balanced people's right to form love relationships while still considering the needs and performance of the team. This position thus echoes the idea of conditional acceptance in the Norwegian guidelines that we referred to in the introduction.

While the athletes were generally positively inclined towards "professionally managed" love-based CASRs, they did express concern that engaging in a relationship with an athlete could compromise one's professional judgement and have a negative influence on team dynamics and performance. This situation relates to the athletic-performance ethic, to be discussed next.

\section{(3) The Athletic-Performance Ethic: Preserving the Sport "Contract"}

The athletes reasoned that both the safeguarding ethic and the love ethic are based on rights. The first focuses on the right to be protected from the risk of being exploited, while the second focuses on the right to form personal relationships and lead a full life-also as an athlete. Conversely, in the athletic-performance ethic, the athletes primarily emphasized the team or sports milieu and collective goals and values. They expressed concern about CASRs leading to preferential treatment and to compromising the coach's ability to focus on sport-related matters. From this perspective, CASRs emerged as being more problematic within team sport settings compared to individual sports. In both scenarios, the interviewees' evaluations were linked to potential consequences that the CASR could have on sport performance, both directly and indirectly, by affecting the social dynamics within the team.

One of the examples concerned a coach-athlete couple who had brought their personal disputes into the sport milieu. The other athletes could clearly see whenever the couple had had a disagreement before practice, because the athlete sometimes shot the ball at the coach instead of the goal (interview 3). The athletes also referred to examples in team sports that had worked well and where the athlete in question had contributed to the team's success, thus illustrating how good performance may overshadow one's general moral stances on CASR.

We had a coach who came to the club, the elite team, and brought his girlfriend. And she was a good player, and then she got the offer to play, of course. Because then [their relationship] 
would enhance the level of performance-you've got a good player and a good coach. And then you had to think, "Okay, fine, they're partners," but they kept [their relationship] professional, and then it wasn't a problem. (Girl 3, int. 15)

The quote above illustrates a case where the athlete-partner was portrayed as an additional asset to the team, which indicates the importance of CASRs not interfering with performance.

The interviewees also referred to high-profile and accomplished female athletes with partner coaches; they offered people such as Heidi Løke and Gunn-Rita Dahle Flesjå as examples of athletes who had made coach-athlete relationships work for themselves.

I don't know, but there are a lot of athletes in individual sports who have partners or spouses or something who are their coaches. Looks like it works. But if [the relationship happens] in a group, I don't know. (Boy 2, int. 8)

Performance success, and how professionally the relationships were handled, hence seemed to function as justification for elite athletes' romantic relationships with their coaches. For the latter, however, the athletes generally found it more difficult to see that CASRs would not interfere with performance in team sports. One primary concern across the interviews was that coaches would give preferential treatment to their partner-athletes at the expense of the others, whether in recreational or elite-level sport. The athletes worried that the coach might grant his partner more playing time than the other players because of the relationship, not because of her athletic performance. Hence, CASRs represented a possible threat to the notion that playing time should be determined based on performance and skill-which complies with the logic of competitive sports. The athletes more readily accepted CASRs if all the athletes in the group were treated equally.

I found [their relationship] okay at practice because he didn't pay her more attention, and I didn't know they were together until after a while. I didn't know they were together when I started. ... It took a while before I understood [their relationship]. (Girl 2, int. 2)

This case shows how professional management of the CASR was a factor in the athletes' assessments, which they viewed in relation to equal treatment of athletes as well as a separation between sport and personal issues.

Some of the athletes also mentioned that CASRs could create tensions within the team and a general lack of trust and respect.

If I felt that I had something I wanted to address that was difficult [to do] in the group, then I should talk to the coach, who I know is in a relationship with one of my team friends. (...) I would've found it difficult to know if he would go to her then [with what we had discussed]. Because they're in a relationship. (Girl 2, int. 18)

We had one such episode in my club. It was a coach who was 10 to 12 years older than the athlete, but [their relationship] didn't affect the performance [of the team]; they were one of the best [teams] in Norway, I think. But there were rumours about him ... [the situation] wasn't good. So [the coach] lost a lot of respect from the team. (Boy 2, int. 3)

In the latter quote, the athlete pointed to dilemmas about CASRs even when he did not think sport performance would be directly affected. Rather, the athlete problematized how the CASR had somehow changed the atmosphere in the team. In his experience, this altered atmosphere related to the players losing respect for the coach because he had acted unprofessionally.

In one of the interviews (interview 20), the participants discussed a particular case with a slowly developing relationship between an athlete and her coach who was more than ten years older than her, in which the initial attraction had presumably started prior to her reaching the legal age of consent. This relationship caused speculations both within and outside her club. At the time, the other athletes felt that the coach had paid her more attention, and that he had done so because of their special relationship and not because she had performed better than the other athletes on the team. The coach later became her official partner once she turned 16, thus making the relationship in accordance with the less strict guidelines for coaches. Even so, the athletes presumed that the relationship might have started earlier (at least on a platonic level) and thus positioned the CASR as being problematic. Hence, even if the relationship had been handled professionally in a legal and official sense, it still could have been interpreted as having been facilitated by a questionable process of grooming. The fact that the couple were still together at the time of the interview (as adults) also featured in the discussion and overshadowed some of the ambivalence that surrounded the story of how the relationship had been established.

This case is thus a salient example of how the activation of the different ethics we have identified-the safeguarding ethic, the love ethic, and the athletic-performance ethic-allows for the relationship to be viewed simultaneously as legitimate and problematic. The relationship could be a case of grooming, or it could represent true and lasting love. If the relationship was a form of lasting love and fell within the realm of the legal, then the athletes could tolerate it, but they understood this particular relationship as being problematic, since it nevertheless felt strange and caused uneasiness.

\section{Discussion and Conclusion}

In this paper, we explore the ambivalence surrounding CASRs in contemporary sport culture, which contrasts with the official position sports organizations take, as reflected in various ethical guidelines and codes of conduct in which CASRs are said to hold no place in sports. As we have shown, this was not the most common position among the young athletes we interviewed. Instead, they shifted between different positions and articulated complex ethical dilemmas related to CASRs. The debates about CASRs appear to have generated a multitude of meanings. This scenario accords well with Swidler's toolkit theory on how culture works, which underlines the fluidity of "culture in action": "People run through different parts of their cultural repertoires, selecting those parts that correspond to the situation or exemplary problem ... that currently holds their attention' (2013, p. 25).

This dynamic is not unique to evaluating CASRs. A similar shifting between repertoires of evaluation is visible in other fields, such as debates within research ethics committees (de Jong, van Zwieten, \& Willems, 2012). Similarly, Swidler (2013) found that when people talked about their reasons for entering into and staying in love relationships, they tried out various rationales-and paid little attention to how they fit together.

When we turn to young athletes' discussions of CASRs, the question then becomes how we can make sense of their sensemaking. This question entails a shift in perspective, from describing the different ethics to identifying the orders of worth or cultural imaginaries that make them legible. We suggest that the activation of 
the different ethics we have described must be simultaneously thought of as an activation of different underlying ideas about the relationship between sport and society. The idea is that the ethics represent valid responses to CASRs - i.e. truths - only within specific imaginaries. This means as well that the ambivalence surrounding CASRs in the sport field is connected to these imaginaries. While the athletes in our study were not asked about such imaginaries directly, from what they said about CASRs, their ideas about the role of sports in society in a sense shone through. The point is that the ethics seem to locate sport in different spheres; either as any other realm of life or separated out and with its own moral logics. We expand on this line of thought in the following discussion.

First, the safeguarding ethic revolves around the vulnerability of children and youths in sport because of their age and subordinate positions. This situation is not unique to sports but applies to all fields of society, for instance in education and types of leisure activities besides sport. Within this ethic, a relationship involving a minor is thought to be just as wrong in sport as it is in other settings where young people depend on adults to learn and develop. Therefore, it makes sense to ban all CASRs involving minors and, to be on the safe side, to regulate CASRs for youths above the legal age of consent. Research on youth vulnerability and exploitation from outside the sports realm suggests that such a ban could be important. Young people tend to see youths, as opposed to children, as being equipped with agency and knowledgeability within sexual encounters (Smette, Stefansen, \& Mossige, 2009). In retrospect, however, people can understand sexual relationships from their younger years in a very different light—as exploitative and problematic - even if a relationship was desired and experienced as being positive at the time (Phillips, 1999).

The love ethic similarly invokes the image of sports as any other sphere of life that people invest their time and energy in-and where they inevitably become close to other people. Some of the participants in our study drew a parallel to work life and made the argument that love relationships in sports are no different from love relationships at work. They happen, and as long as they occur between consenting adults, they are fine. These evaluations are premised on the possibility of separating out relationships that fall short of being both legal and reciprocal, and hence at odds with modern ideals of lasting love relationships as "pure relationships," uncompromised by power relations and dependencies (Giddens, 1992).

As we see it, the athletic-performance ethic operates within a different sphere, where sport comes across as a separate field with its own logic and morality. One parallel that comes to mind is the military and other "total institutions." This separating out of sport was visible in the athletes' reasoning about the conditional acceptance of reciprocal and love-based CASRs. Within this ethic, the athletes viewed CASRs with suspicion because of their possibly negative impact on team dynamics, but they could tolerate them if handled professionally. But the athletes also explained that they could accept relationships within their teams or performance groups, even if they also caused friction among the other athletes (for instance by undermining the athletes' trust in their coach), given that the couple or one of the partners helped the team or group's performance. Hence, an intense focus on sport-related goals and values could overshadow problematic aspects of some CASRs.

The athletes' reasoning about this issue is understandable and quite predictable if viewed in light of what Coakley and Pike (2009), drawing on Hughes and Coakley (1991), define as the "sport ethic." The sport ethic is a particular moral ethos constituted by an interrelated set of norms used to "guide and evaluate attitudes and actions in the social world of power and performance sports" (p. 186). Two of the primary norms in this ethic are that athletes must (1) give the sport priority over all other things and (2) always be committed to improving and achieving perfection. Our point is that the premise of this ethic is that sport goes above and beyond the rules of life elsewhere. Simply banning CASRs would not make sense in this evaluative frame, since CASRs can boost an athlete's or team's performance.

In conclusion, we understand the ambivalence surrounding CASRs as something other than a collision between different positions that can be designated as right or wrong. The ambivalence is instead produced by a shifting between cultural frames that also pertain to the relationship between sport and society. What is moral to do with CASRs relates to the status of the sport realm, as being either elevated or not. Our analysis has also revealed that the cultural frames the athletes applied could serve to emphasize or deemphasize potentially problematic aspects of legal CASRs. At the same time, the discussions showed that sport organizations are limited in what they could legitimately regulate in the eyes of the athletes, especially with love-based CASRs.

In terms of implications, we advise sport organizations to, first, treat CASRs as a complex and multifaceted social phenomenon, and not as a moral vice that can be "regulated away." Second, we suggest that there is merit in engaging sport leaders, coaches, and athletes in discussions about ethical dilemmas in sport, including but not restricted to CASRs. Such discussions could contribute towards building and retaining critical awareness of the potential for abuse of power in sport. They could sensitize athletes to the possibility of exploitation-which general ideas about athletes as being strong and competent may overshadow (cf. Fasting, Brackenridge \& Walseth, 2007).

\section{Notes}

1. In Norwegian, "Unngå doble relasjoner. Dersom et gjensidig forhold etableres bør situasjonen tas opp og avklares åpent i miljøet"; accessed 20 June 2018 from https://www.idrettsforbundet.no/tema/retningslinjer/ seksuell-trakassering-og-overgrep/.

2. In Norwegian, "Misbruk ikke din makt og autoritet. Det er nulltoleranse for seksuell tilnærming og intim kontakt med utøvere"; accessed 5 May 2018 from www.idrettsforbundet.no.

3. Because the first two groups were not given the questionnaire, we have information on 84 of the 94 participants.

4. The films are available online: https://www.idrettsforbundet.no/tema/ retningslinjer/seksuell-trakassering-og-overgrep/.

\section{Acknowledgments}

This study was supported by The Research Programme on Violence in Close Relationships, financed by The Norwegian Ministry of Justice and Public Security, and the research project Sport in Young People's Lives, financed by The Norwegian Ministry of Culture. We would like to thank our colleagues from the latter project for their valuable comments on earlier drafts of this paper, as well as researchers from both institution $\mathrm{x}$ and institution $\mathrm{y}$, who helped us conduct the interviews. We also wish to express our thanks to the anonymous reviewers for their very constructive help. The authors have no conflicts of interest to declare related to the research presented in this paper. 


\section{References}

Boltanski, L., \& Thévenot, L. (2000). The reality of moral expectations: A sociology of situated judgement. Philosophical Explorations, 3(3), 208-231. doi:10.1080/13869790008523332

Boltanski, L., \& Thévenot, L. (2006). On justification: Economies of worth. Princeton, NJ: Princeton University Press.

Brackenridge, C., \& Fasting, K. (2005). The grooming process in sport: Narratives of sexual harassment and abuse. Auto/Biography, 13(1), 33-52. doi:10.1191/0967550705ab016oa

Braun, V., \& Clarke, V. (2006). Using thematic analysis in psychology. Qualitative Research in Psychology, 3(2), 77-101. doi:10.1191/ 1478088706qp063oa

Bringer, J.D., Brackenridge, C.H., \& Johnston, L.H. (2002). Defining appropriateness in coach-athlete sexual relationships: The voice of coaches. Journal of Sexual Aggression, 8(2), 83-98. doi:10.1080/ 13552600208413341

Coakley, J., \& Pike, E. (2009). Sports in society: Issues and controversies. London, UK: McGraw Hill.

de Jong, J.P., van Zwieten, M.C., \& Willems, D.L. (2012). Ethical review from the inside: Repertoires of evaluation in Research Ethics Committee meetings. Sociology of Health \& Illness, 34(7), 1039-1052. PubMed ID: 22332841 doi:10.1111/j.1467-9566.2012.01458.x

Fasting, K., \& Brackenridge, C. (2005). The grooming process in sport: Case studies of sexual harassment and abuse. Auto/Biography, 13(1): 33-52. doi:10.1191/0967550705ab016oa

Fasting, K., Brackenridge, C., \& Walseth, K. (2007). Women athletes' personal responses to sexual harassment in sport. Journal of Applied Sport Psychology, 19(4), 419-433. doi:10.1080/10413200701599165

Fasting, K., Sand, T.S., \& Sisjord, M.K. (2018). Coach-athlete sexual relationships: Coaches' opinions. International Journal of Sports Science \& Coaching, 13(4), 463-470. doi:10.1177/1747954117753807

Giddens, A. (1992). The transformation of intimacy: Sexuality, love and eroticism in modern societies. Cambridge, UK: Polity Press.

Grover, R.L., \& Nangle, D.W. (2003). Adolescent perceptions of problematic heterosocial situations: A focus group study. Journal of Youth and Adolescence, 32(2), 129-139. doi:10.1023/A:1021809918392

Henry, S.G., \& Fetters, M.D. (2012). Video elicitation interviews: A qualitative research method for investigating physician-patient interactions. Annals of Family Medicine, 10(2), 118-125. PubMed ID: 22412003 doi:10.1370/afm.1339

Hughes, R., \& Coakley, J. (1991). Positive deviance among athletes: The implications of overconformity to the sport ethic. Sociology of Sport Journal, 8(4), 307-325. doi:10.1123/ssj.8.4.307

Johansson, S. (2013). Coach-athlete sexual relationships: If no means no does yes mean yes? Sport, Education and Society, 18(5), 678-693. doi:10.1080/13573322.2013.777662
Johansson, S. (2018). 'Am I sexually abused?' Consent in a coach-athlete lesbian relationship. Sport, Education and Society, 23(4), 311-323. doi:10.1080/13573322.2016.1202819

Johansson, S., Kenttä, G., \& Andersen, M.B. (2016). Desires and taboos: Sexual relationships between coaches and athletes. International Journal of Sports Science \& Coaching, 11(4), 589-598. doi:10. $1177 / 1747954116654777$

Johansson, S., \& Larsson, H. (2017). 'This might be him; the guy I'm gonna marry': Love and sexual relationships between female elite-athletes and male coaches. International Review for the Sociology of Sport, 52(7), 819-838. doi:10.1177/1012690 215626593

Jowett, S., \& Meek, G.A. (2000). The coach-athlete relationship in married couples: An exploratory content analysis. Sport Psychologist, 14(2), 157-175. doi:10.1123/tsp.14.2.157

Lang, M., Mergaert, L., Arnaut, C., \& Vertommen, T. (2018). Genderbased violence in EU sport policy: Overview and recommendations. Journal of Gender-Based Violence, 2(1), 109-118. doi:10.1332/ 239868018X15155986979910

Nielsen, J.T. (2001). The forbidden zone: Intimacy, sexual relations and misconduct in the relationship between coaches and athletes. International Review for the Sociology of Sport, 36(2), 165-182. doi:10. 1177/101269001036002003

Owton, H., \& Sparkes, A.C. (2017). Sexual abuse and the grooming process in sport: Learning from Bella's story. Sport, Education and Society, 22(6), 732-743. doi:10.1080/13573322.2015. 1063484

Phillips, L.M. (1999). Recasting consent: Agency and victimization in adult-teen relationships. In S. Lamb (Ed.), New versions of victims: Feminists struggle with the concept (pp. 82-107). New York, NY: New York University Press.

Silber, I.F. (2003). Pragmatic sociology as cultural sociology: Beyond repertoire theory? European Journal of Social Theory, 6(4), 427-449. doi:10.1177/13684310030064004

Smette, I., Stefansen, K., \& Mossige, S. (2009). Responsible victims? Young people's understandings of agency and responsibility in sexual situations involving underage girls. Young, 17(4), 351-373. doi:10.1177/110330880901700402

Swidler, A. (1986). Culture in action: Symbols and strategies. American Sociological Review, 51, 273-286. doi:10.2307/2095521

Swidler, A. (2013). Talk of love: How culture matters. Chicago, IL: University of Chicago Press.

Tjelta, L.I., Tønnessen, E., \& Enoksen, E. (2014). A case study of the training of nine times New York Marathon winner Grete Waitz. International Journal of Sports Science \& Coaching, 9(1), 139-158. doi:10.1260/1747-9541.9.1.139 